\title{
Cervical Versus Vaginal, and Sublingual Misoprostol for Labor Induction at Term Parturient: a Randomized Double-blind Clinical Trial
}

Mahtab Dadashaliha

Department of Obstetrics and Gynecology,children growth research center,research institute for prevention of non-communicable diseases,Qazvin university of medical science,Qazvin,Iran

Somayeh Fallah ( $\sim$ Shimafalah@ymail.com )

Qazvin University of Medical Sciences https://orcid.org/0000-0001-9724-7955

\section{Monirsadat Mirzadeh}

Metabolic diseases research center,research institute for prevention of non-communicable diseases,Qazvin university of medical science,Qazvin,Iran

Research article

Keywords: Misoprostol, induction, Term pregnancy

Posted Date: January 5th, 2021

DOI: https://doi.org/10.21203/rs.3.rs-137297/v1

License: (c) (i) This work is licensed under a Creative Commons Attribution 4.0 International License. Read Full License 


\section{Abstract}

Background. The study will attempt to evaluate the safety and effectiveness of intracervical misoprostol in comparison with intravaginal and sublingual for the induction of labor at term.

Methods. three hundred term pregnancies requiring induction of labor were treated with $50 \mu \mathrm{g}$ of misoprostol intracervical, sublingual and vaginal. Participants were randomly allocated into three groups of 100 . The dose was repeated every 4 hours until adequate uterine contraction and Bishop score were achieved. The duration of induction to delivery, time to active phase, the rate of delivery, and the need for cesarean section were compared in three groups. Additionally, labor course and side effects were recorded and analyzed.

Results. Labor was successfully induced in all cases, most (63\%) of which required a single dose of misoprostol. Ninety-three (93.0\%) cervical patients proceeded to spontaneous vaginal delivery, also this figure was the same in the vaginal and sublingual group 83 (83.0\%), The other 41 cases received cesarean delivery with more indications failure to progress and meconium-stained liquor. The results showed that $278(92.7 \%)$ deliveries were achieved in less than 10 hours. Time from start of medication to the active phase of labor and delivery were $3.01 \pm 0.86$ and $6.1 \pm 1.3$ hours in the Cervical group, $4.2 \pm$ 0.66 and $8.4 \pm 0.92$ hours in the sublingual group, and $5.06 \pm 1.1$ and $9.2 \pm 1.5$ hours in the vaginal group respectively $(p<0.001)$. Cesarean rate was lower in the cervical group than the two other groups $(p=0.05)$. No significant differences were observed between the study groups in terms of Apgar score and meconium-stained amniotic fluid. Moreover, no maternal and neonatal complication were seen.

Conclusion: In addition to the sublingual and intravaginal routes of administration, intracervical misoprostol at a single dose of $50 \mu \mathrm{g}$ appears to be an effective method for induction of labor in women with an unfavorable cervix. Similar to all medical interventions, a discussion of the risks, benefits, and alternatives to induction of labor with this medication in each individual woman should be undertaken prior to treatment.

Trial registration: This clinical study was approved by the Iranian Registry of Clinical Trials (http://www.irct.ir) with the IRCT ID: IRCT20190415043278N1, Registration and approval date was 201905-13 and 2019-05-27 respectively.

\section{Background}

Induction means stimulation of contractions before the spontaneous labor begins (with or without rupture of the membranes). In cases where the cervix is closed and there is no effusion, induction of labor often begins with Cervical ripening of the cervix and in this process, prostaglandins are commonly used to soften and open the cervix (1). Induction of labor is one of the common interventions in the field of midwifery (2). And is one of the international recommendations of the World Health Organization (WHO) in 2011. Induction of labor in cases where the benefits to the mother or fetus outweigh the benefits of continuing the pregnancy, Finds indication which is included postdate pregnancies, gestational diabetes, 
gestational hypertension, preeclampsia, oligohydramnios, unreliable fetal status, or fetal pathologies such as intrauterine growth retardation (3). Cervical preparation is one of the most substantial factors in the success of labor induction. The findings of the study found that in women who had prepared the cervix before induction, the rate of cesarean section was lower than in women who were directly induced by oxytocin. Induction of labor with the unripening cervix can also result in failure of induction (4) Or prolonged labor and delivery with the assistance of instruments (5). This has adverse psychological and physical impacts on the pregnant mother and decreases satisfaction with delivery (6). Other research indicated that when the cervix was not ready, attempts were made to induce labor, decrease the success of natural birth and increase the probability of cesarean (7). The condition of the cervix is regarded as the most important indicator of the effectiveness of labor induction. The Bishop scoring system was one of the most popular techniques for predicting the efficacy of labor induction in 1964 (8). The bishop's score is derived from the amount of the cervix's degree of softness, effacement, and dilatation (1). There is a maximum score of 13. Studies have shown that women with a score of 9 or greater have a higher rate of successful induction of vaginal delivery (8). When the bishop score is less than 6 , cervical preparation is required (5). To date, numerous procedures to soften the cervix before labor induction have been developed, which are primarily categorized into two classes of different types of cervical and pharmacological dilators (9). The best option is a technique with adequate cervix preparation that does not involve detrimental maternal and fetal side effects (10). The use of prostaglandin products (misoprostol PGE1), dinoprostone (PGE2, Pyridyl), oxytocin, dexamethasone and mechanical techniques such as stripping, artificial membrane rupture (Amniotomy), extra-amniotic saline injection, trans cervical balloons and hygroscopic cervical dilators are primarily pharmacological techniques (1). Misoprostol has been listed on the list of important obstetric drugs by the World Health Organization and the American College of Obstetricians and Gynecologists and advises the use of prostaglandins to induce it, as it has been shown that the rate of vaginal delivery increases within 24 hours after labor induction and the need for oxytocin decreases $(3,11)$. Misoprostol is currently an analog of prostaglandin E1 as an oral pill approved by the FDA and is marketed for the prevention and treatment of gastrointestinal injuries, but is used for various indications in obstetrics and gynecology, such as medical abortion, labor induction, cervical ripening prior to surgery, and postpartum hemorrhage treatment (11). Misoprostol can be administered on buccally vaginal, sublingual, oral, and rectal basis. However, as a teratogenic drug, misoprostol is known. Cranial abnormalities, bladder exstrophy, arthrogryposis, cranial nerve palsies, and facial malformations are associated disorders. This range of congenital complications is due to uterine contraction-induced vascular disorders, which are very rare in the population (about 1\%) (12).

Other side effects of this therapy include uterine hyperstimulation and fetal heart rate disturbances that have been taken into account in numerous studies. However, so far, no unique dosage or administration method has been recorded without causing such side effects. However, in Cochrane research, the optimal dosage is 25 micrograms per 4 to 6 hours to soften the cervix, which is correlated with the lowest rate of uterine hyperstimulation. One of the unusual but dangerous complications associated with the use of this drug is uterine rupture (13). Various trials have been undertaken comparing the types of misoprostol and labor outcomes. The results of previous studies have found vaginal misoprostol, compared to cervical 
dinoprostone and oxytocin, is a more powerful induction alternative. In these trials, the dosage used ranged from $25 \mu \mathrm{g}$ every 2 to 3 hours to $50 \mu \mathrm{g}$ every 4 hours to $100 \mathrm{Ug}$ every 6 to 12 hours. The authors also noted that, with or without a change in fetal heart rate, higher doses were associated with uterine tachysystole. On the other hand, the dose reduction of misoprostol had no effect on decreasing the efficacy of the drug (5) and there was no significant difference between the two groups in neonatal admission to the NICU and the neonatal Apgar score (14).

Studies have shown that $50 \mu \mathrm{g}$ dose comparing $25 \mu \mathrm{g}$ doses, decreasing the time interval between contractions and oxytocin requirements, improved vaginal delivery rate, but the safety of this dose is still uncertain (15). Overall, because of the importance of the subject and the absence of a comparable report on the use of cervical misoprostol, in this review, the efficacy and safety of cervical misoprostol with vaginal misoprostol and sublingual misoprostol was compared with the 50-ug labor induction dose in female candidates for termination of pregnancy.

\section{Methods}

A randomized, double-blind, three-arm study was performed at two hospitals in Qazvin, Iran, from July 2019 to September 2020. Kosar was a university hospital while Mehregan was a privately owned. Both hospitals' research ethics boards accepted the report. In advance of participating in the study an informed consent form signed by all volunteers. This clinical study was approved in the Iranian Registry of Clinical Trials (http://www.irct.ir) with the IRCT ID: IRCT20190415043278N1, date approval 2019-0527.

Inclusion criteria consisted in Nuliparity, singleton pregnancy, gestational age 37 weeks or greater, cephalic presentation, live fetus, cervical Bishop score $\leq 5$, estimated fetal weight $<4000$ grams. Women were excluded in case of premature rupture of membranes, Placenta Previa, placenta abruption, fetal malformations, Multiparity, severe preeclampsia, abnormal fetal heart rate tracings or signs of active labor at admission and previous uterine scars. Other exclusion criteria were the presence of contraindications for the use of PG analogues, including glaucoma, asthma, epilepsy, and allergy. The misoprostol used in this study (Cytotec, Searle, England) was an analog of prostaglandin E1 in $200 \mathrm{mg}$ tablets. The tablets were cut into quarters for the application of labor induction, each portion containing $50 \mathrm{mg}$.

The tablets were packed in the containers of the cervix, sublingual (SL) or vagina (V) and then numbered between 1 and 300. Only the responsible pharmacist had knowledge of the contents of each container. By a computerized randomization sequence, the pouches were numbered. A blocked randomization was made to guarantee that the groups were of equal size(16). Participants underwent obstetric examinations, including Bishop scoring at admission upon entering the delivery room and recorded by one of the midwives, then obtained one of these containers. Due to blindness, $50 \mathrm{mg}$ of misoprostol was applied to the cervical canal, vaginal posterior fornix or sublingual to induce labor by a gynecologist or the second investigator. Also, women were not informed about the treatment that they offered. In order to 
avoid information bias in the estimation of Bishop Scores, three midwives were responsible for vaginal examination who were unaware of the procedure, and midwifery vaginal examinations were coordinated with each other prior to the outset of the study.

Dosing was repeated every 4 hours until 3 or more uterine contractions lasting 40 s occur within minutes, or when the maximum of 4 doses has been reached. In the absence of active labor 6 hours after the final dosage of misoprostol or if cervical dilation did not advance for 2 hours, it was reckoned a failure to induce labor so that intravenous oxytocin for augmentation or cesarean section was taken. Maternal vital signs and gastrointestinal symptoms were evaluated every 2 hours and samples was monitored for both uterine contraction and fetal heart rate.

The primary outcome was vaginal delivery rate, the time from the first administration of misoprostol to labor initiation and delivery; labor duration; total of doses of misoprostol applied. Secondary outcomes were adverse drug effects during treatment and infant outcomes. Adverse effects included disorders of uterine contractility (Tachysystole and Hyperstimulation syndrome), gastrointestinal symptoms such as nausea, vomiting, hyperthermia, diarrhea, and headache. We adopted the definition of Heuser et al(17) in which uterine tachysystole was defined by any occurrence of five or more contractions within 10 min, averaged over three consecutive 10-min periods, Uterine hyperstimulation syndrome was defined as uterine tachysytole with concurrent foetal heart rate decelerations or bradycardia, hypertonus as a single contraction with duration of at least 2 min. Neonatal outcome consisted of the rates of 5-min Apgar score $<7$, umbilical artery/venous $\mathrm{pH}$, presence of meconium and NICU hospitalization. In cases where the Apgar score was less than 7, arterial blood gas cord blood data were collected.

A demographic questionnaire containing information such as age, parity, abortion history and body mass index was initially filled out. Another questionnaire is the primary form of delivery that is available in each delivery room in which labor progress and delivery of the infant was completed during labor and after delivery. Several questions such as dilatation and effacement of the cervix, fetal head station, Bishop Score estimation, status of water bags, side effects of medicines, infant birth weight, Apgar score, and amniotic fluid transparency were collected.

Based on the same study (18) and the average amount of changes in bishop score and considering $10 \%$ drop in sample size, 104 people in each group were calculated. Participants were randomly split into three groups. Statistical analysis was processed using SPSS software (version 20), and $P<0.05$ was considered significant. Continuous data are described as the mean \pm standard deviation (SD), while categorical data are described as the frequency and percentage. Dichotomous variables were compared between the groups using the Chi square test or Pearson, and continuous variables were analyzed using the One-way ANOVA test. The differences in the induction-onset of labor intervals were evaluated by Tukey test. Covariance analysis (ANCOVA) was used to compare the effects of some variable on time to active phase.

\section{Results}


In the first study, 312 healthy women were chosen to participate in the study, of which 12 women who withdrew consent were absent. Thus, 300 women were allocated for cervical preparation into three intervention groups. Figure 1 summarizes the flow map. Comparisons of the female features of the three groups are demonstrated in Table 1. The three groups had no substantial differences prior to the interventions in maternal height, weight, gestational age, parity, and maternal age, abortion history, and Bishop score. In three classes (cervical-30.3 percent, sublingual-34 percent, vaginal 34.9 percent), most of them were primigravida. In the cervical group, the mean gestational age at admission was $39.4 \pm 0.78$ weeks, and in the other two groups, $39.1 \pm 1$.9. Post-dates were the most common indication for induction in three classes. In the sample group, the highest number of women had a Bishop's score of 1-2, representing $0.79 \%$ (cervical) and $0.9 \%$ (sublingual, vaginal), respectively, and this was not statistically significant $(p=0.38)$. The baseline characteristics were comparable in three the groups $(p>0.05)$. For most of the items, the differences between the three groups were minimal.

The effects of three interventions on time between administration to the active phase and time between preparations to delivery can be seen in Table 2. There were significant differences between groups in time to delivery and time to active phase. Two group comparisons using the Tukey test revealed that the mean time to the active phase $(p<0.001)$ and time to delivery $(p<0.001)$ in the cervical group were significantly lower than in the vaginal and sublingual groups. Moreover, in the sublingual community, the mean time to the active process $(p<0.001)$ and time to delivery $(p<0.001)$ were significantly lower than in the vaginal group. One hundred and eighty-nine (63\%) patients needed only one dose of misoprostol. Two doses were needed for the other hundred and eleven (37 percent). The statistics also indicated that the cesarean frequency was different in the three groups $(p=0.05)$. Failure to progress ( 4 cases) and meconiumstained liquor (3 cases) were the reasons for cesarean in the cervical group. In the sublingual community, 17 cases of cesarean delivery were identified with indications of non-progress (five cases) and meconium-stained liquor, respectively (twelve cases). Finally, In the vaginal group 11 and 6 case were accompanied with meconium-stained and failure to progress respectively. No case with fetal distress or uterine hyper tonicity was seen.

The comparison of Apgar infants in the three groups is displayed in Table 3. In the three classes, the firstminute Apgar score did not vary $(p=0.1)$ but was different after 5 minutes $(p<0.001)$. The Apgar score of one and five minutes between the three groups was not significant. In the NICU, no infants were hospitalized. Fetal distress and death in infant not was seen.

In the analysis, covariance analysis (ANCOVA) was used according to this table to try to account for the effects of age, bishop score, and groups on time to the active phase. The period to the active phase is substantially altered by Bishop scores and intervention groups, but age had no significant impact. Adjusted R Squared $=.461$ suggests that the bishop variable and the intervening variable can estimate approximately 46 percent of the time for active phase changes (Table 4).

\section{Discussion}


This study is the first double-blind, prospective randomized controlled clinical trial examining the effectiveness and safety of vaginal, sublingual intracervical misoprostol in labor induction in Iran during term pregnancy. We observed that $50 \mu \mathrm{g}$ intracervical misoprostol considerably increased the incidence of onset of labor within 24 hours relative to sublingual and vaginal administration, and reduced the induction-onset of labor interval or vaginal delivery within $24 \mathrm{~h}$ from the beginning of labor induction without significantly raising the maternal and fetal complications and adverse effects, which is consistent with other previous studies on the topic(19).

Previous studies have shown that sublingual intake or intravaginal misoprostol administration is successful for labor induction. The ideal dosage and route of administration, however, remain contentious. Here the intracervical route of administration is recorded and a favorable outcome in labor induction was achieved in the word. In this study, the majority of $189(63 \%)$ of our patients required a single induction dose of $50 \mu \mathrm{g}$, which is similar to other investigations $(19,20)$. In the cervical groups, the time from initial administration to regular contractions was $3.01 \pm 0.86$ hours, a figure better than the intravaginal and sublingual results of the same dose of misoprostol $(21,22)$. Approximately $92.7 \%$ of women achieved vaginal delivery below $10 \mathrm{~h}$ and $7.3 \%$ achieved vaginal induction up to $10 \mathrm{~h}$, of which the cervical community reported the least time to delivery with a mean of $6.1 \pm 1.3 \mathrm{~h}$. In the cervical group the rate of spontaneous vaginal delivery (93\%) appeared to be better than to that reported by Souizi et al. (64.5\%) (23), Veena (76.8\%) (22), Girija (60\%) (24), Jahromi (25) using routes of administration sublingual or vaginal. On the other hand, there was no note of the time difference between the vaginal and sublingual groups in the study variation. However, the time intervals associated with the sublingual community were shorter for just one hour $(\mathrm{p}<0.001)$. It is also possible to display intracervical and sublingual administration as a more effective route than vaginal agents. Gattás's study_ A randomized, placebo-controlled trial of $12.5 \mu \mathrm{g}$ sublingual and $25 \mu \mathrm{g}$ vaginal dose administration found that in the sublingual community, the duration between the first dose of misoprostol and the onset of labor was shorter (26). Sublingual misoprostol was also found in the Ayati's study to be as successful as vaginal misoprostol for term labor induction. Sublingual misoprostol, however, has the benefit of easy administration and may be more fitting than vaginal misoprostol (27). So the reports were in accordance with previous findings (28). Although the findings were not in harmony with the Feitosa's report, which found that 25ug sublingual misoprostol administration was neither more effective nor safer than the same vaginally administered dose (29). Due to the small sample size, it may be possible to use a higher bishop score of samples $(\leq 6)$, with low doses of misoprostol that does not allow conclusive conclusions to be drawn. The required intracervical dose of misoprostol is almost 2 times lower than the intravaginal or sublingual dosage $(20,21,29)$. While there is a lack of pharmacokinetic evidence on the local administration of misoprostol (30). it is conceivable that intracervical misoprostol directly enters the target organ, thus optimizing the local impact and decreasing systemic absorption (20). In addition, it was found that the sublingual route of administration has an area similar to vaginal administration under the curve, but more rapid absorption and higher peak levels than either vaginal or oral administration, which may support the findings of our literature (12). 
There were no cases of Gastrointestinal involvement, tachysystole and hyperstimulation, as already seen in our research. This is a problem for patients treated with misoprostol, and is noted in several studies(19, $20,31)$. More studies indicate that the incidence of hyperstimulation and tachysystole is important to the dose, as shown by an incidence of 0.0 percent with $25 \mu \mathrm{g}(32), 18-25 \%$ with $50 \mu \mathrm{g}$ (19), uterine activity should be closely monitored following the use of misoprostol. In three groups, the evaluation of the caesarean indication was similar, including failure to progress and meconium-stained liquor. Similar to studies by Souizi et al $(7 \%)$, Dasgupta and Roudsari et al $(10 \%)$, the cesarean rate was $7 \% .(23,33,34)$. No statistically significant differences have however been reported. Fortunately, the neonatal result was nice in the three groups as all neonates were born alive with a median Apgar score of 9, 10 at 1 and 5 min respectively and no child was hospitalized in NICU.

\section{Conclusions}

Our findings indicate that intracervical administration of misoprostol is effective in inducing labor without side effects on mothers during pregnancy and without any obvious adverse effects on the fetus. In females with the unripened cervical disorder, it may decrease labor period and time to delivery. The effects of sublingual routes of administration on women and the fetus were similar or more beneficial. Further studies on the use of higher-dose cervical misoprostol on primiparas provide a good direction for ongoing research on this subject.

\section{Abbreviations}

FDA: US Food and Drug Administration

BMl: Body mass index.

\section{Declarations}

\section{Ethics approval and consent to participate}

This study has been approved by the Clinical Research Ethics Committee of Qazvin University of medical science. http://ethics.research.ac.ir/IR.QUMS.REC.1397.409,_date approval 2019.3.13.Each patient signed an informed consent regarding data collection for scientific purpose prior to their admission to the study.

\section{Consent for publication}

Not applicable.

\section{Availability of data and materials}

The dataset used and/or analyzed during the current study are available from the corresponding author on reasonable request. 


\section{Competing interests}

The authors declare that they have no competing interests.

\section{Funding}

This research received no external funding.

\section{Authors' contributions}

S. F and M.D conceived and designed the study. And M. M critically evaluated the manuscript. M.D performed the examination samplings and following pregnant women during delivery, S. F was a major contributor in writing the manuscript and M.M analyzed and interpreted the patient data regarding the labor progress. All authors significantly contributed to the development and implementation of the protocol. All authors read and approved the final manuscript.

\section{Acknowledgements}

The researchers express their gratitude from respected all participants in research, and all who made precious contributions to this study.

\section{Publisher's Note}

Springer, Nature remains neutral with regard to jurisdictional claims in published maps and institutional affiliations.

\section{References}

1. Cunningham F, Leveno K, Bloom S, Spong CY, Dashe J. Williams obstetrics, 24e: Mcgraw-hill; 2014.

2. Greenberg V, Khalifeh A, editors. Intracervical Foley balloon catheter for cervical ripening and labor induction: A review. Seminars in perinatology; 2015:

Elsevier. https://doi.org/10.1053/j.semperi.2015.07.005

3. Patte C, Deruelle P. A critical appraisal of the misoprostol removable, controlled-release vaginal delivery system of labor induction. International journal of women's health. 2015;7:889. doi: 10.2147/IJWH.S62372.

4. Sanchez-Ramos L. Induction of labor. Obstetrics and Gynecology Clinics. 2005;32(2):181200. https://doi.org/10.1016/j.ogc.2004.12.004.

5. Hofmeyr GJ, Gülmezoglu AM, Pileggi C. Vaginal misoprostol for cervical ripening and induction of labour. Cochrane Database of Systematic Reviews. 2010(10). https://doi.org/10.1002/14651858.CD000941.pub2.

6. Clark SL, Miller DD, Belfort MA, Dildy GA, Frye DK, Meyers JA. Neonatal and maternal outcomes associated with elective term delivery. American journal of obstetrics and gynecology. 
2009;200(2):156. e1-. e4. https://doi.org/10.1016/j.ajog.2008.08.068.

7. Durie $D$, Lawal A, Zegelbone P, editors. Other mechanical methods for pre-induction cervical ripening. Seminars in perinatology; 2015: Elsevier. https://doi.org/10.1053/j.semperi.2015.07.006.

8. Ezebialu IU, Eke AC, Eleje GU, Nwachukwu CE. Methods for assessing pre-induction cervical ripening. Cochrane Database of Systematic Reviews.

2015(6). https://doi.org/10.1002/14651858.CD010762.pub2.

9. Adeniji O, Oladokun A, Olayemi O, Adeniji O, Odukogbe A, Ogunbode O, et al. Pre-induction cervical ripening: transcervical foley catheter versus intravaginal misoprostol. Journal of obstetrics and gynaecology. 2005;25(2):134-9. https://doi.org/10.1080/01443610500040737.

10. Gilstrop M, Sciscione A, editors. Induction of labor-Pharmacology methods. Seminars in perinatology; 2015: Elsevier. https://doi.org/10.1053/j.semperi.2015.07.009.

11. Bolla D, Weissleder SV, Radan A-P, Gasparri ML, Raio L, Müller M, et al. Misoprostol vaginal insert versus misoprostol vaginal tablets for the induction of labour: a cohort study. BMC pregnancy and childbirth. 2018;18(1):149. doi: https://doi.org/10.1186/s12884-018-1788-z.

12. Allen R, O'Brien BM. Uses of misoprostol in obstetrics and gynecology. Reviews in obstetrics and gynecology. 2009;2(3):159.PMCID: PMC2760893.

13. Kundodyiwa TW, Alfirevic Z, Weeks AD. Low-dose oral misoprostol for induction of labor: a systematic review. Obstetrics \& Gynecology. 2009;113(2):374-83. doi: 10.1097/AOG.0b013e3181945859.

14. Liu A, Lv J, Hu Y, Lang J, Ma L, Chen W. Efficacy and safety of intravaginal misoprostol versus intracervical dinoprostone for labor induction at term: A systematic review and meta-analysis. Journal of Obstetrics and Gynaecology Research. 2014;40(4):897-906. https://doi.org/10.1111/jog.12333.

15. Stephenson ML, Wing DA, editors. Misoprostol for induction of labor. Seminars in perinatology; 2015: Elsevier. https://doi.org/10.1053/j.semperi.2015.07.008.

16. Friedman LM, Furberg CD, DeMets DL, Reboussin DM, Granger CB. The randomization process. Fundamentals of clinical trials: Springer; 2015. p. 123-45. https://doi.org/10.1007/978-3-319-18539$\underline{2} 6$

17. Heuser CC, Knight S, Esplin MS, Eller AG, Holmgren CM, Richards D, et al. Tachysystole in term labor: incidence, risk factors, outcomes, and effect on fetal heart tracings. American journal of obstetrics and gynecology. 2013;209(1):32. e1-. e6. https://doi.org/10.1016/j.ajog.2013.04.004

18. Redling K, Schaedelin S, Huhn EA, Hoesli I. Efficacy and safety of misoprostol vaginal insert vs. oral misoprostol for induction of labor. Journal of perinatal medicine. 2019;47(2):17682. https://doi.org/10.1515/jpm-2018-0128.

19. Chang Y-K, Chen W-H, Yu M-H, Liu H-S. Intracervical misoprostol and prostaglandin E2 for labor induction. International Journal of Gynecology \& Obstetrics. 2003;80(1):23-

8. https://doi.org/10.1016/S0020-7292(02)00333-8. 
20. Liu HS, Chu TY, Chang YK, Yu MH, Chen WH. Intracervical misoprostol as an effective method of labor induction at term. International Journal of Gynecology \& Obstetrics. 1999;64(1):4953. https://doi.org/10.1016/S0020-7292(98)00228-8.

21. Gupta H, Singh U, Mehrotra S. Comparative evaluation of $25 \mu \mathrm{g}$ and $50 \mu \mathrm{g}$ of intravaginal misoprostol for induction of labor. The Journal of Obstetrics and Gynecology of India. 2010;60(1):514. https://doi.org/10.1007/s13224-010-0009-0.

22. Veena B, Samal R, Inbaraj LR, George CE. Sublingual Misoprostol (PGE1) Versus Intracervical Dinoprostone (PGE2) Gel for Induction of Labour: A Randomized Control Trail. The Journal of Obstetrics and Gynecology of India. 2016;66(1):122-8. https://doi.org/10.1007/s13224-015-0820-8.

23. Souizi B, Mortazavi F, Haeri S, Borzoee F. Comparison of vaginal misoprostol, laminaria, and isosorbide dinitrate on cervical preparation and labor duration of term parturient: a randomized double-blind clinical trial. Electronic physician. 2018;10(5):6756.doi:10.19082/6756.

24. Girija S, Manjunath AP. Comparison of two dosing regimens of vaginal misoprostol for labour induction: a randomised controlled trial. Journal of the Turkish German Gynecological Association. 2009;10(4):220. PMCID: PMC3939169.

25. Jahromi BN, Poorgholam F, Yousefi G, Salarian L. Sublingual versus vaginal misoprostol for the induction of labor at term: a randomized, triple-blind, placebo-controlled clinical trial. Iranian journal of medical sciences. 2016;41(2):79. PMCID: PMC4764971.

26. Gattás DS, de Amorim MM, Feitosa FE, da Silva-Junior JR, Ribeiro LC, Souza GF, et al. Misoprostol administered sublingually at a dose of $12.5 \mu \mathrm{g}$ versus vaginally at a dose of $25 \mu \mathrm{g}$ for the induction of full-term labor: a randomized controlled trial. Reproductive Health. 2020;17:1-

9. https://doi.org/10.1186/s12978-020-0901-8.

27. Ayati S, Vahidroodsari F, Farshidi F, Shahabian M, Aghaee MA. Vaginal versus sublingual misoprostol for labor induction at term and post term: a randomized prospective study. Iranian journal of pharmaceutical research: IJPR. 2014;13(1):299. PMCID: PMC3985259.

28. Lapuente-Ocamica O, Ugarte L, Lopez-Picado A, Sanchez-Refoyo F, Lasa IL, Echevarria O, et al. Efficacy and safety of administering oral misoprostol by titration compared to vaginal misoprostol and dinoprostone for cervical ripening and induction of labour: study protocol for a randomised clinical trial. BMC pregnancy and childbirth. 2019;19(1):14. https://doi.org/10.1186/s12884-0182132-3.

29. Feitosa F, Sampaio Z, Alencar Jr C, Amorim M, Passini Jr R. Sublingual vs. vaginal misoprostol for induction of labor. International Journal of Gynecology \& Obstetrics. 2006;94(2):915. https://doi.org/10.1016/j.ijgo.2006.04.031.

30. Windrim R, Bennett K, Mundle W, Young DC. Oral administration of misoprostol for labor induction: a randomized controlled trial. Obstetrics \& Gynecology. 1997;89(3):392-

7. https://doi.org/10.1016/S0029-7844(96)00523-6.

31. Jindal P, Avasthi K, Kaur M. A Comparison of Vaginal vs. Oral Misoprostol for Induction of LaborDouble Blind Randomized Trial. The Journal of Obstetrics and Gynecology of India. 2011;61(5):538- 
42. https://doi.org/10.1007/s13224-011-0081-0.

32. Bolnga J, Morris M, Laman M, editors. Safety and effectiveness of oral misoprostol for induction of labour in a resource-limited setting: a dose escalation study. AUSTRALIAN \& NEW ZEALAND JOURNAL OF OBSTETRICS \& GYNAECOLOGY; 2018: WILEY 111 RIVER ST, HOBOKEN 07030-5774, NJ USA. https://doi.org/10.1186/s12884-017-1483-5.

33. Dasgupta E, Singh G. Vaginal misoprostol vs vaginal misoprostol with estradiol for labor induction: a prospective double blind study. The Journal of Obstetrics and Gynecology of India. 2012;62(1):47-51. https://doi.org/10.1007/s13224-012-0156-6.

34. Roudsari FV, Ayati S, Ghasemi M, Mofrad MH, Shakeri MT, Farshidi F, et al. Comparison of vaginal misoprostol with foley catheter for cervical ripening and induction of labor. Iranian journal of pharmaceutical research: IJPR. 2011;10(1):149. PMCID: PMC3869583.

\section{Tables}

Table 1: Baseline demographic data and clinical characteristics

\begin{tabular}{|c|c|c|c|c|c|}
\hline Characteristic variable & cervical group & sublingual group & vaginal group & Total & $\mathrm{p}$-value \\
\hline $\begin{array}{l}\text { Age }(y)(M \pm S D) \\
0.07 \\
\text { Parity }\end{array}$ & \multicolumn{2}{|c|}{$29.3 \pm 5.2$} & $28.1 \pm 4.7$ & $27.7 \pm 5.1$ & $28.4 \pm 5.08$ \\
\hline Primiparity & $53(30.3 \%)$ & $61(34.9 \%)$ & $61(34.9 \%)$ & $175(100 \%)$ & 0.41 \\
\hline Multipara & $47(37.6 \%)$ & $39(31.2 \%)$ & $39(31.2 \%)$ & $125(100 \%)$ & \\
\hline \multicolumn{6}{|l|}{ Gravidity } \\
\hline Primigravida & $48(31.45 \%)$ & $50(32.7 \%)$ & $55(35.9 \%)$ & $153(100 \%)$ & 0.59 \\
\hline Multigravida & $52(35.4 \%)$ & $50(34 \%)$ & $45(30.6 \%)$ & $147(100 \%)$ & \\
\hline Previous abortion: $\mathrm{n}(\%)$ & $\begin{array}{l}\text { yes } 21(42.9 \%) \\
\text { No } 79(31.5 \%)\end{array}$ & $\begin{array}{l}11(22.4 \%) \\
89(35.5 \%)\end{array}$ & $\begin{array}{l}17(34.7 \%) \\
83(33.1 \%)\end{array}$ & $\begin{array}{l}49(100 \%) \\
251(100 \%)\end{array}$ & 0.15 \\
\hline $\begin{array}{l}\text { Gestational Age }(\mathrm{M} \pm \mathrm{SD}) \\
\mathrm{BMI}(\mathrm{kg} / \mathrm{m} 2)(\mathrm{M} \pm \mathrm{SD})\end{array}$ & $\begin{array}{l}39.4 \pm 0.78 \\
23.6 \pm 3.3\end{array}$ & $\begin{array}{l}39.1=1.9 \\
24.4 \pm 3.4\end{array}$ & $\begin{array}{l}39.1 \pm 1.8 \\
24.03 \pm 3.7\end{array}$ & $\begin{array}{c}39.2 \pm 1.6 \\
24 \pm 3.5\end{array}$ & $\begin{array}{l}0.40 \\
0.33\end{array}$ \\
\hline Bishop score $(\mathrm{M} \pm \mathrm{SD})$ & $0.79=0.49$ & $0.90 \pm 0.83$ & $0.92 \pm 0.76$ & $0.87 \pm 0.71$ & 0.38 \\
\hline Birth weight $(\mathrm{M} \pm \mathrm{SD})$ & $2.2=0.52$ & $2.2 \pm 0.62$ & $2.2 \pm 0.56$ & $2.2 \pm 0.57$ & 0.99 \\
\hline
\end{tabular}

BMI: Body mass index.

Table 2: Comparisons of labor and delivery outcomes in three groups 
Time to Active phase (hours) $(\mathrm{M} \pm \mathrm{SD})$

Time to delivery (hours) $(\mathrm{M} \pm \mathrm{SD})$

Single dose of misoprostol: $\mathrm{n}(\%)$

Mode of delivery: $\mathrm{n}(\%)$

Vaginal delivery

Cesarean

Birth weight $>3500: \mathrm{n}(\%)$

Gastrointestinal implication

Hyper stimulation

Tachysystol

Failure to progress: $\mathrm{n}(\%) \quad$ Yes

$95(33.3 \%)$
$3.01 \pm 0.86$

$6.1 \pm 1.3$

$98(51.9 \%)$

93(93)

$7(7.0)$

$\begin{array}{cc}\text { Yes } & 4(23.5 \%) \\ \text { NO } & 95(34.3 \%) \\ & 0 \\ & 0 \\ & 0 \\ & 4(26.7 \%)\end{array}$

$4.2 \pm 0.66$
$8.4 \pm 0.92$

$63(33.3 \%)$

$83(83)$

$17(17.0)$

$8(47.1 \%)$

$89(32.1 \%)$

0

0

0

$5(33.3 \%)$
$5.06 \pm 1.1<0.001$

$9.2 \pm 1.5 \quad<0.001$

$28(14.8 \%) \quad 0.000 \quad 189(63 \%)$

$83(83)$

$17(17.0)$

$0.05 \quad 259(86.3 \%)$

$5(29.4 \%) \quad 0.42$

$93(33.6 \%)$

0

0

$6(40 \%)$

0.81

NO

$96(33.7 \%)$

Table 3: Effects of interventions on Apgar score and meconium -stained Liquor

\begin{tabular}{|c|c|c|c|c|}
\hline Variable & cervical group & sublingual group & vaginal group & p-value \\
\hline First minute Apgar $(\mathrm{M} \pm \mathrm{SD})$ & $9.0 \pm 0.00$ & $8.6 \pm 1.7$ & $8.7 \pm 1.2$ & 0.11 \\
\hline Five minute Apgar $(\mathrm{M} \pm \mathrm{SD})$ & 10.00 & 10.00 & 10.00 & 0.00 \\
\hline \multicolumn{2}{|c|}{ Meconium-stained Liquor: n (\%) Yes 3(11.5\%) } & $12(46.2 \%)$ & $11(42.3 \%)$ & \multirow[t]{2}{*}{0.46} \\
\hline & No $(35.4 \%)$ & $88(32.1 \%)$ & $89(32.5 \%)$ & \\
\hline Fetus Distress & 0 & 0 & 0 & - \\
\hline Need to NICU & 0 & 0 & 0 & - \\
\hline Death & 0 & 0 & 0 & - \\
\hline
\end{tabular}

Table 4: Effects of variable on time to active phase

\begin{tabular}{|llll|}
\hline & Mean Square & $F$ & Adjusted $p$-value \\
\hline BISHOP & 7.669 & 8.991 & .003 \\
\hline Age & .841 & .986 & .321 \\
\hline Group & 106.036 & 124.315 & .000 \\
\hline
\end{tabular}

\section{Figures}




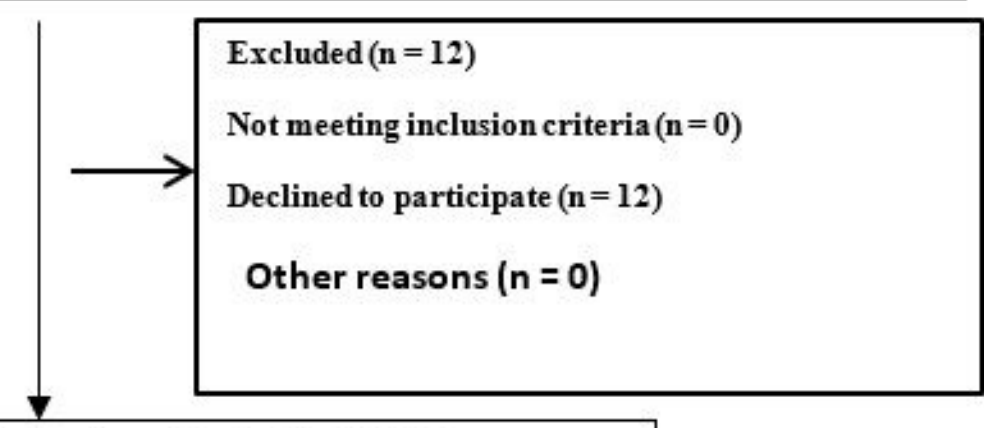

Random allocation via simple randomization $(\mathrm{N}=\mathbf{3 0 0}$ )

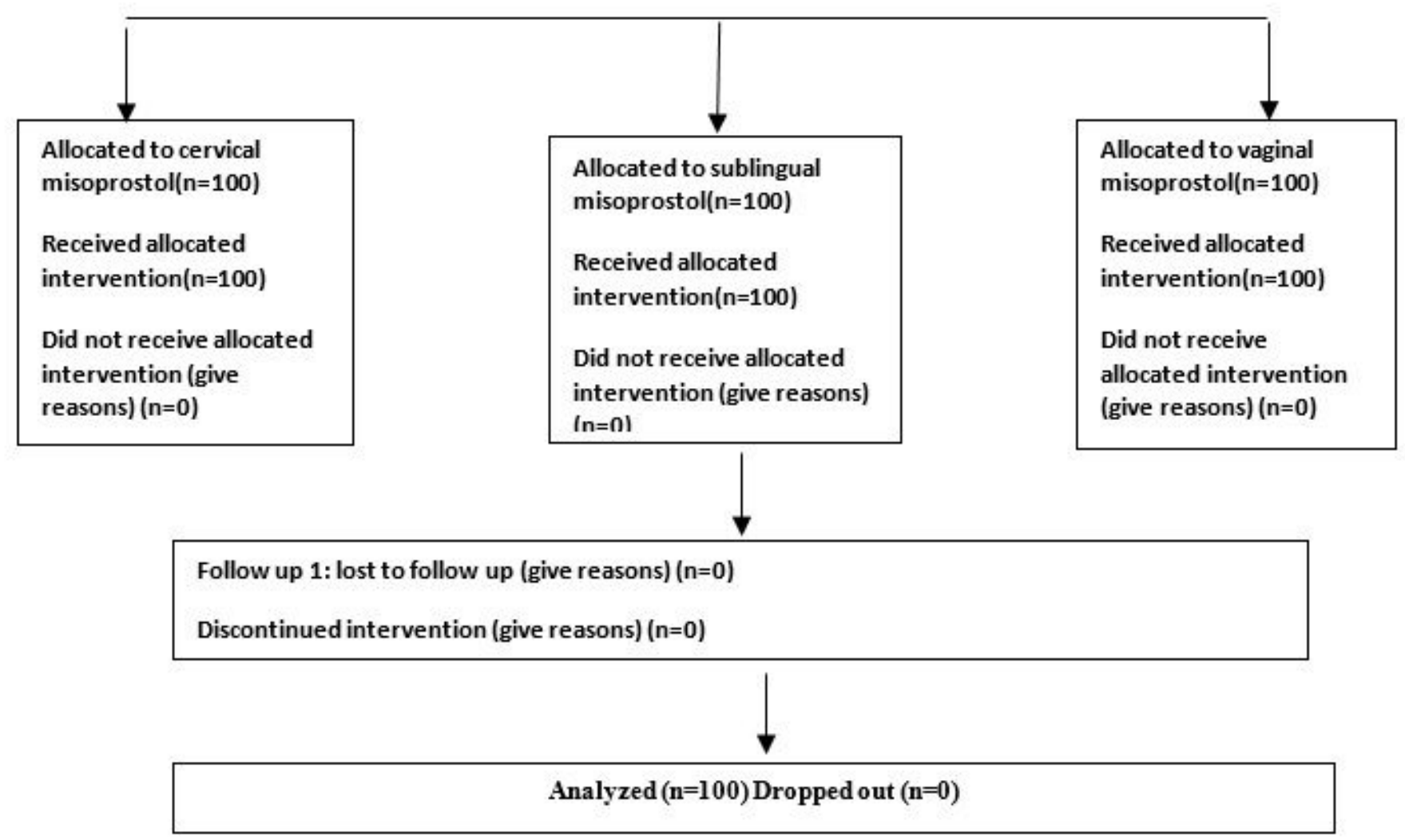

Figure 1

Consort diagram of study 